\title{
Qualidade da água de um ecossistema lótico urbano
}

\section{Water quality of an urban lotic ecosystem}

\section{Ronaldo Fia ${ }^{1}$, Hugo César Tadeu ${ }^{2}$, João Paulo Cunha de Menezes ${ }^{3}$, \\ Fátima Resende Luiz Fia ${ }^{4}$ e Luiz Fernando Coutinho de Oliveira ${ }^{5}$}

\author{
${ }^{1}$ Universidade Federal de Lavras - Departamento de Engenharia, CP 3037, UFLA, 37.200-000, Lavras - MG, Brasil \\ ronaldofia@deg.ufla.br \\ ${ }^{2}$ Universidade Federal de Lavras - Laboratório de Resíduos Químicos \\ Diretoria de Meio Ambiente, CP 3037, UFLA, 37.200-000, Lavras - MG, Brasil \\ tadeuhc@prefeitura.ufla.br; \\ 3,4,5 Universidade Federal de Lavras - Departamento de Engenharia, CP 3037, UFLA, 37.200-000, Lavras - MG, Brasil
}

jpaulo@posgrad.ufla.br; fatimarlf@deg.ufla.br; coutinho@deg.ufla.br

\begin{abstract}
RESUMO
A qualidade das águas é fortemente infuenciada pelo uso e manejo dos solos de uma bacia bidrográfica e pelo regime bídrico. No período chuvoso bá arraste de materiais superficiais, e na estiagem, aumento das concentraçoes de poluentes advindos dos despejos, pelo fato da redução da vazão. Assim, o objetivo deste trabalho foi analisar a variação espaço-temporal da qualidade da água e das características tróficas dos principais cursos de água na microbacia do Ribeirão Vermelho em Lavras-MG. Determinou-se o Índice de Qualidade de Água (IQA) e o Índice do Estado Trófico (IET) no periodo chuvoso (verão) e no período de estiagem (inverno). Com base nos resultados obtidos em três amostragens durante o período chwvoso e três no período de estiagem, verificou-se valores de IQA entre 31 e 64 no período do verão e de 33 a 67 no período de inverno. Em relação à trofia dos mananciais, foram verificados valores de IET entre 48 e 50 no periodo chuvoso e de 38 a 45 no periodo de estiagem, variando de oligotrófico a eutrófico. Diante dos resultados obtidos, verificou-se que o Ribeirão Vermelho e seus afluentes apresentam forte influência das formas de uso e ocupação do solo constatada pela entrada de matéria orgânica e de nutrientes nos sistemas hídricos por meio do lançamento de esgoto doméstico sem tratamento e pela agropecuária na rede de drenagem da bacia.
\end{abstract}

Palavras Chave: Índice de qualidade de água. Índice de estado trófico. Eutrofização. Poluição hidrica.

\begin{abstract}
Water quality is strongly influenced by the use and management of soils in a watershed and the rainfall. During the rainy season there is surface runoff and during the dry season, increased concentrations of pollutants from releases, because of reduced flow. This work aimed to evaluate the spatial and temporal variation of water quality and trophic characteristics of the main watercourses in the watershed of Ribeirão Vermelho in Lavras - MG. The Water Quality Index (IQA) and the Trophic State Index (IET) during the rainy season (summer) and the dry season (winter) were determined.. IQA values were obtained in three samples during the rainy period and three in the dry season. They were between 31 and 64 during the summer and 33 and 67 in the winter. Results obtained showed that the Ribeirão Vermelho and its tributaries are strongly influenced by forms of land use and occupation found by the input of organic matter and nutrients into the water systems from discharging untreated sewage and by agriculture in the watershed drainage system.
\end{abstract}

Keywords: Water quality index. Trophic state index. Eutrophication. Water pollution. 


\section{INTRODUÇÃO}

Os efeitos combinados da urbanização e das demais atividades antropogênicas associadas ao rápido crescimento populacional das últimas décadas são facilmente visualizados nos ecossistemas aquáticos. Muitos rios, córregos, lagos e reservatórios têm sido degradados em consequência do impacto crescente das atividades humanas (WENGRAT; BICUDO, 2011; BUZELLI; CUNHA-SANTINO, 2013).

Esta situação é particularmente visível em áreas de densa população humana, especialmente no meio urbano, onde cursos de água recebem uma grande quantidade de esgoto doméstico e industrial, como também sedimentos e resíduos sólidos urbanos. Deste modo, rios urbanos são transformados, perdendo suas características naturais e alterando a qualidade de suas águas (YU et al., 2013; ZHOU et al., 2011; ORTEGA; CARVALHO, 2013).

Diante desse quadro, o monitoramento das águas superficiais destaca-se como um importante instrumento de gestão, independente do tamanho da bacia, possibilitando a tomada de decisão por parte dos órgãos ambientais. Esse monitoramento propicia a obtenção de dados qualitativos e quantitativos da água, evidenciando requisitos de qualidade traduzidos, de forma generalizada e conceitual, em função de seus usos previstos. Sob esse aspecto, os Índices de Qualidade de Água (IQA) (IGAM, 2005) e o Índice do Estado Trófico (IET) (Lamparelli, 2004) constituem-se em ferramentas que viabilizam uma avaliação rápida das características da água, em relação às fontes de poluição.

O IQA constitui-se em uma ferramenta de avaliação da condição de qualidade dos corpos de águas, indicando o grau de contaminação devido aos materiais orgânicos, nutrientes e sólidos, que normalmente são indicadores de poluição. Esse índice foi desenvolvido pela National Sanitation Foundation (TYA-
GI et al., 2013; AKKOYUNLU; AKINER, 2012) e adaptado por órgãos ambientais de São Paulo (CETESB) e Minas Gerais (IGAM). Além do IQA, outros índices são utilizados, como o índice do estado trófico (IET), que tem por finalidade classificar corpos d'água em diferentes graus de trofia. O IET avalia a qualidade da água quanto ao enriquecimento por nutrientes e seu efeito, relacionado ao crescimento excessivo das algas ou ao aumento de infestação de macrófitas aquáticas (CETESB, 2013; IGAM, 2013).

Pelo fato da qualidade das águas ser fortemente influenciada pelo uso e manejo dos solos de uma bacia hidrográfica, o regime hídrico influencia o arraste de materiais superficiais no período chuvoso; bem como o aumento das concentrações de poluentes advindos dos despejos, pelo fato da redução do volume de água escoado no período de estiagem (LEMOS et al., 2010; SANTI, et al., 2012; CUNHA et al., 2013).

Neste contexto, no presente estudo objetivou-se caracterizar a variação sazonal e espacial das variáveis físicas, químicas e biológicas de uma microbacia urbana, abrangendo diferentes períodos e avaliar a qualidade de suas águas com o Índice de Qualidade da Água (IQA) e do Índice do Estado Trófico (IET).

\section{MATERIAL E MÉTODOS}

\section{Área de estudo}

Localizada na Mesorregião Sul do Estado de Minas Gerais, entre as coordenadas geográficas $21^{\circ} 11^{\prime}$ a $21^{\circ} 16^{\prime}$ de latitude Sul e $44^{\circ} 57^{\prime}$ a $45^{\circ} 03^{\prime}$ de longitude Oeste, a bacia hidrográfica do Ribeirão Vermelho, afluente do Rio Grande, está inserida no município de Lavras (Figura 1). A nascente do Ribeirão Verme-

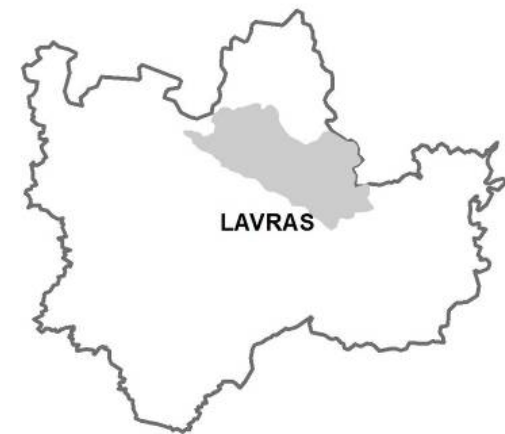

Bacia Ribeirão Vermelho

- Pontos de coleta Ocupaçao da bacia

Área Agrícola

Pastagem

Área Urbana

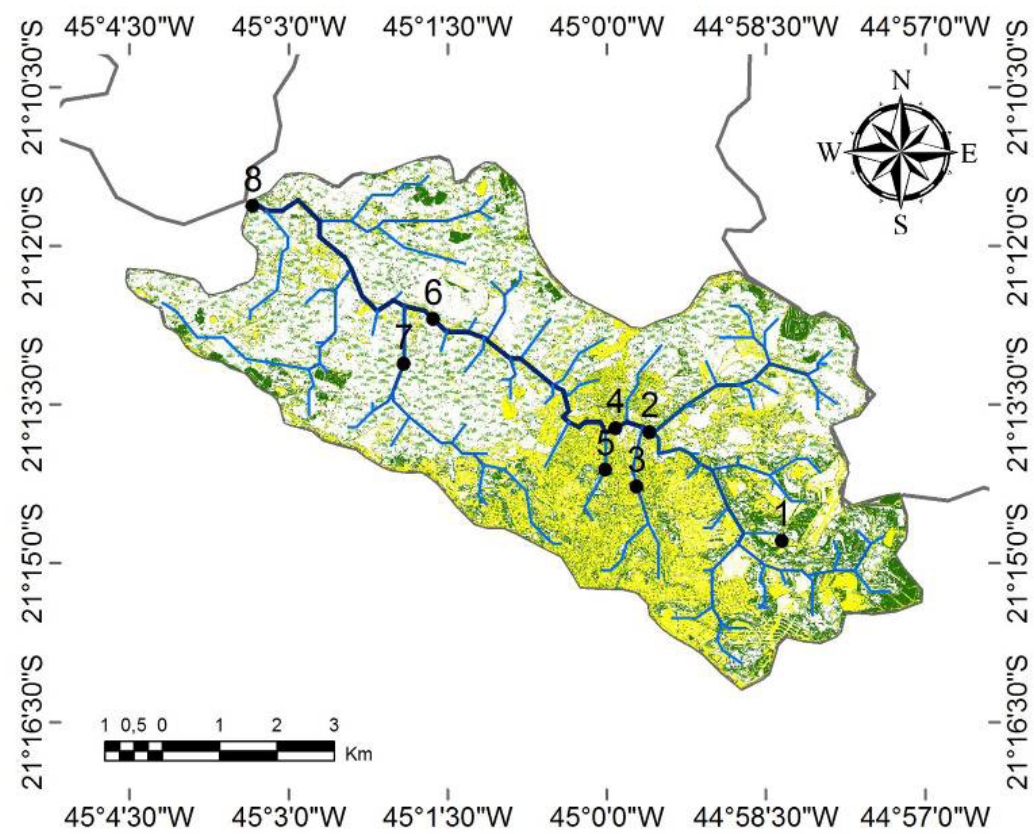

$45^{\circ} 4^{\prime} 30 " \mathrm{~W} \quad 45^{\circ} 3^{\prime} 0 " \mathrm{~W} \quad 45^{\circ} 1^{\prime} 30 " \mathrm{~W} \quad 45^{\circ} 0^{\prime} 0 " \mathrm{~W} \quad 44^{\circ} 58^{\prime} 30 " \mathrm{~W} \quad 44^{\circ} 57^{\prime} 0^{\prime \prime} \mathrm{W}$

Figura 1 - Localização da bacia hidrográfica do Ribeirão Vermelho em Lavras-MG, distribuição dos pontos amostrais e principais usos e ocupação do solo na bacia 
lho, assim como seus principais afluentes, encontra-se na zona urbana da cidade de Lavras que pelo censo de 2010 apresentou 92.200 habitantes (IBGE, 2010). Após percorrer aproximadamente 15 km, o Ribeirão Vermelho deságua no Rio Grande, um dos principais formadores da bacia hidrográfica do Paraná.

Apesar de a cidade de Lavras possuir uma estação de tratamento de esgoto doméstico na bacia hidrográfica em estudo, parte do esgoto é lançada ao longo do percurso no Ribeirão Vermelho e seus afluentes. Além disso, ao cortar a zona rural do município, há diversas fontes de poluição difusa como plantações e criatórios de animais, principalmente bovinos de forma extensiva.

Segundo a classificação climática de Köppen, o clima da região é classificado como Cwa, temperado chuvoso (mesotérmico) com inverno seco e verão chuvoso, subtropical e temperatura anual variando em torno de $19,3^{\circ} \mathrm{C}$, tendo nos meses mais quente e mais frio, temperaturas médias de $22,1^{\circ} \mathrm{C}$ e $15,8^{\circ} \mathrm{C}$, respectivamente. A precipitação anual normal (1961-1990) na bacia é de $1.530 \mathrm{~mm}$ (Figura 2) (Brasil, 1992).

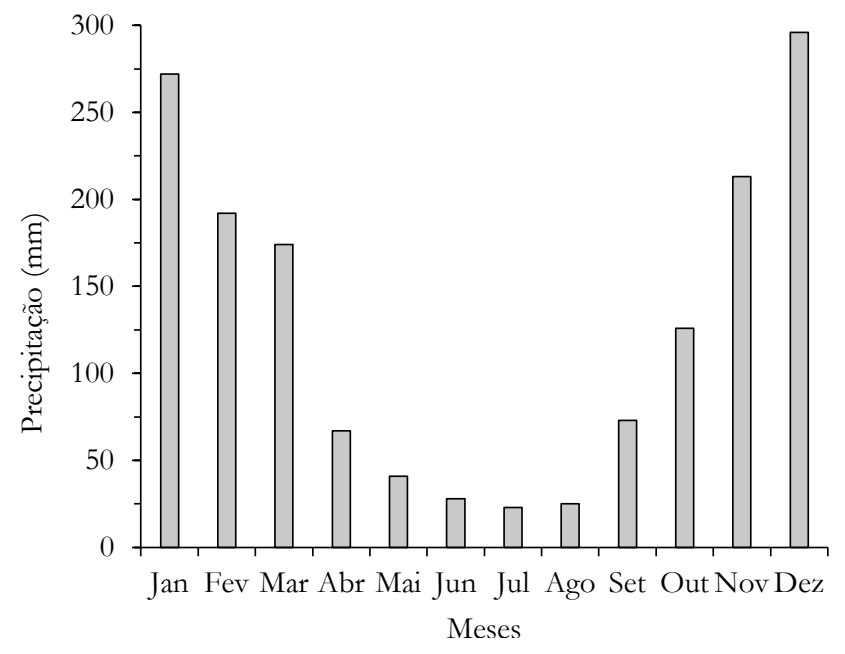

Figura 2 - Totais médios de precipitações mensais em Lavras, no período de 1961 a 1990

\section{Coleta e análise da água}

Foram coletadas amostras em seis períodos diferentes entre janeiro e setembro de 2011, representando duas épocas amostrais: período chuvoso (verão) e período de estiagem (inverno) (Figura 3), em oito pontos ao longo da bacia do Ribeirão Vermelho: P1 - Nascente do Ribeirão Vermelho; P2 - Ribeirão Vermelho à montante do Córrego Centenário; P3 - Córrego Centenário; P4 - Ribeirão Vermelho à montante do Córrego do Antigo Matadouro; P5 - Córrego do Antigo Matadouro; P6 - Ribeirão Vermelho à montante do Córrego Campestre; P7 Córrego Campestre; e P8 - Foz do Ribeirão Vermelho no Rio Grande (Figura 1). Os pontos de amostragem foram escolhidos de acordo com o posicionamento dos tributários do córrego e da distribuição das possíveis fontes de poluição.

A forma de amostragem foi do tipo manual e as amostras coletadas próximas à superfície (ABNT, 1987), em função da pequena profundidade dos cursos de água.

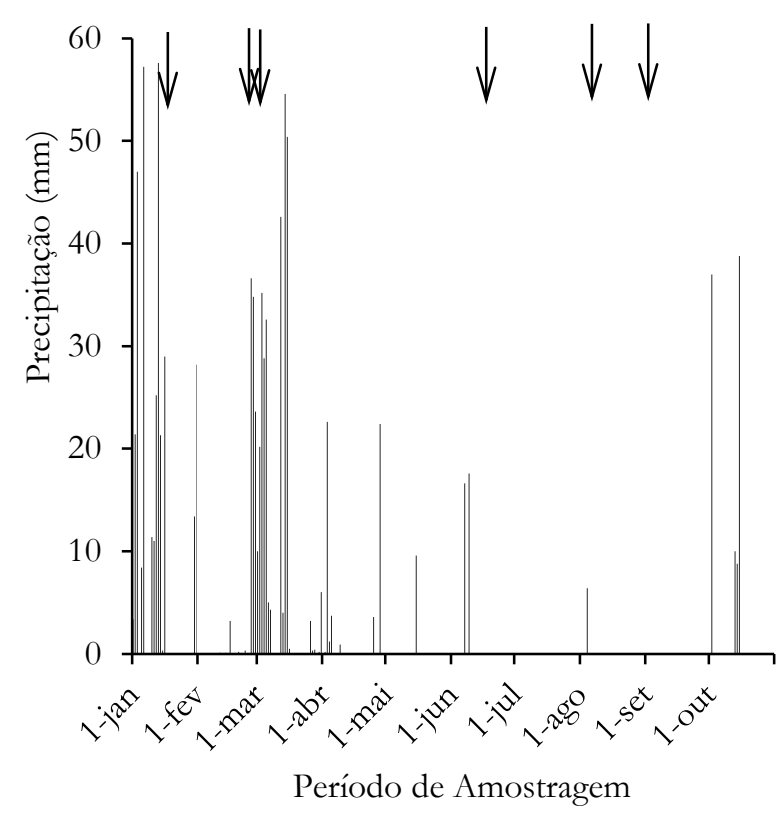

Figura 3 - Dias de amostragem, indicados pelas setas, e dias de ocorrência de precipitação durante o período amostral

Foram determinadas as seguintes características físicas, químicas e biológicas: potencial hidrogeniônico $(\mathrm{pH})$, por potenciometria; turbidez, pelo método nefelométrico; demanda bioquímica de oxigênio (DBO), pelo método iodométrico; nitrato $\left(\mathrm{NO}_{3}{ }^{-}\right)$, por colorimetria pelo método do salicilato; fósforo $(\mathrm{P})$, por colorimetria pelo método do vanado-molibdato; sólidos totais (ST), pelo método gravimétrico; oxigênio dissolvido (OD), pelo método iodométrico; coliformes termotolerantes, pelo método dos tubos múltiplos (APHA et al., 2005). As medições de temperatura foram feitas no momento das coletas, utilizando-se termômetro de mercúrio.

Para estimativa da vazão dos cursos de água utilizou-se o método do flutuador (AZEVEDO NETO, 1998).

Os dados foram submetidos à comparação de médias entre os períodos (verão e inverno) com nível de significância de $5 \%$ e teste de Scott-Knott para avaliar a diferença entre os pontos avaliados utilizando-se o software SISVAR (FERREIRA, 2011).

\section{Cálculo dos índices de qualidade}

Para o cálculo do IQA foi utilizada a metodologia proposta pelo Instituto Mineiro de Gestão das Águas (IGAM, 2005) utilizando a Equação 1. Os pesos relativos a cada parâmetro estão apresentados na Tabela 2.

$$
\text { IQA }=\prod_{i=1}^{n} q_{i}{ }^{w}
$$

Em que, IQA - Índice de Qualidade de Água (0-100); $\mathrm{W}_{\mathrm{i}}$ - peso relativo do i-ésimo parâmetro; e $\mathrm{q}_{\mathrm{i}}$ - valor do subíndice relativo ao i-ésimo parâmetro. 
Tabela 1 - Parâmetros de qualidade de água e os respectivos pesos relativos utilizados no cálculo do Índice de Qualidade de Água (IGAM, 2005)

\begin{tabular}{lc}
\hline Parâmetros & Pesos $\left(\mathrm{w}_{\mathrm{i}}\right)$ \\
\hline Oxigênio dissolvido & 0,17 \\
Coliformes Termotolerantes & 0,15 \\
$\mathrm{pH}$ & 0,12 \\
DBO & 0,10 \\
Nitrato & 0,10 \\
Fósforo & 0,10 \\
Turbidez & 0,08 \\
Sólidos torais & 0,08 \\
Variação da temperatura & 0,10 \\
\hline
\end{tabular}

A partir dos valores de IQA as águas foram classificadas de acordo com a Tabela 2.

Tabela 2 - Classificação das águas naturais, de acordo com os valores do Índice de Qualidade de Água (IQA) observados (IGAM 2005)

\begin{tabular}{lc}
\hline IQA & Classificação quanto à qualidade \\
\hline $90<$ IQA $<100$ & Excelente \\
$70<$ IQA $<90$ & Bom \\
$50<$ IQA $<70$ & Médio \\
$25<$ IQA $<50$ & Ruim \\
$0<$ IQA $<25$ & Muito Ruim \\
\hline
\end{tabular}

Para o cálculo médio do IET, utilizou-se do modelo matemático proposto por Lamparelli (2004) para ambientes lóticos (Equação 2).

$$
\mathrm{IET}=10 \cdot\left[6-\left(\frac{0,42-0,36 \cdot \ln (\mathrm{P})}{\ln 2}\right)\right]-20
$$

Em que, IET - Índice de Estado Trófico proposto por Lamparelli; e P - concentração de fósforo total, $\mu \mathrm{g} \mathrm{L} \mathrm{L}^{-1}$.

Para a interpretação do estado trófico dos corpos aquáticos foram utilizados os limites apresentados na Tabela 3.

Tabela 3 - Classificação das águas naturais, de acordo com os valores do Índice de Estado Trófico (IET) observados (LAMPARELLI, 2004)

\begin{tabular}{lc}
\hline IET & Classificação quanto à trofia \\
\hline IET $>67$ & Hipereutrófico \\
$63<$ IET $\leq 67$ & Supereutrófico \\
$59<$ IET $\leq 63$ & Eutrófico \\
$52<$ IET $\leq 59$ & Mesotrófico \\
$47<$ IET $\leq 52$ & Oligotrófico \\
IET $\leq 47$ & Ultraoligotrófico \\
\hline
\end{tabular}

\section{RESULTADOS E DISCUSSÃO}

Por se tratar de um período chuvoso, as estimativas de vazão feitas nos cursos de água no verão apresentaram maiores valores de vazão quando comparadas ao inverno (Tabela 4). A variação na vazão pode refletir diretamente na qualidade da água, principalmente quanto ao efeito diluição dos poluentes, tal como observado por Coradi et al. (2009 a,b) e Santi et al. (2012). Por outro lado, no período chuvoso o escoamento superficial aumenta, e maior se torna o carreamento de substâncias, como verificado por Lemos et al. (2010).

A temperatura diferiu entre os períodos de inverno e verão $(p<0,05)$, sendo mais elevada no verão e em direção à foz (P8) (Tabela 4). Corpos de água naturais apresentam variações de temperaturas sazonais devido ao regime climático normal (OLIVEIRA et al., 2008). Fatores como a latitude, altitude, estação do ano, período do dia e profundidade, influenciam a temperatura superficial. Como os cursos de água avaliados são pouco profundos, houve, provavelmente, influência da temperatura ambiente na temperatura da água. Além disso, o aumento do canal do ribeirão ao longo do percurso provocou maior exposição à radiação solar e, consequentemente, aumento da temperatura da água. Outro fator que pode ter influenciado na temperatura da água foi a escassa vegetação ciliar observada no curso de água.

Os valores de $\mathrm{pH}$ observados nas amostras diferiram estatisticamente entre os períodos de verão e inverno $(\mathrm{p}<0,05)$, exceto na foz (P8), apresentando maiores valores no período de chuva onde foram verificadas as maiores vazões (Tabela 4). $\mathrm{O}$ pH é influenciado pela quantidade de matéria orgânica a ser decomposta, sendo que, no geral, quanto maior a quantidade disponível, confirmados pelos valores de $\mathrm{DBO}$, menor o $\mathrm{pH}$, devido à biodegradação, que produz ácidos orgânicos e gás carbônico (OLIVEIRA et al., 2009). Deste modo, quanto menor as vazões, maiores a concentrações de matéria orgânica, diminuindo os valores de $\mathrm{pH}$. Parte dos esgotos da cidade de Lavras são lançamentos nos cursos de água que cortam o município sem tratamento prévio, o que contribui para o aumento da matéria orgânica nos mesmos. A redução dos valores de $\mathrm{pH}$ na nascente (P1) durante o inverno podem estar relacionada à matéria orgânica proveniente da mata ciliar que circunda o local.

Outro fator que influencia o $\mathrm{pH}$ da água é a temperatura da mesma; quanto maior a temperatura menor é o valor de $\mathrm{pH}$, diferentemente do observado neste trabalho. Assim, acredita-se na maior influência da matéria orgânica sobre a variável $\mathrm{pH}$. Ao contrário do observado neste trabalho, Silva et al. (2008) verificaram a diminuição dos valores de $\mathrm{pH}$ com o aumento da temperatura da água e das precipitações pluviométricas. Segundo Esteves (2011), os valores de pH nos rios brasileiros são bastante amplos, tendendo a ser ligeiramente alcalinos devido à presença de carbonatos e bicarbonatos.

Os maiores valores médios de turbidez foram observados no verão, exceto para P1 e P5. No entanto, os sólidos totais (ST) foram semelhantes tanto no inverno quanto no verão para os mesmos pontos avaliados. Assim, acredita-se que a maior parte dos ST observados no verão foram sólidos em suspensão, responsáveis pela turbidez das águas. Em função do arraste de 
Fia et al.: Qualidade da água de um ecossistema lótico urbano

Tabela 4. - Valores médios das variáveis mensuradas nas amostras de água coletadas em diferentes períodos do ano (chuvoso e estiagem), nos diferentes pontos amostrais ao longo do Ribeirão Vermelho (P1, P2, P4, P6 e P8) e seus principais afluentes (P3, P5 e P7)

\begin{tabular}{|c|c|c|c|c|c|c|c|c|c|}
\hline Variáveis & & P1 & P2 & P4 & P6 & P8 & P3 & P5 & P7 \\
\hline \multirow{2}{*}{$\mathrm{pH}$} & PC & 7,5 & 7,4 & 7,6 & 7,6 & 7,6 & 7,6 & 7,6 & 7,6 \\
\hline & $\mathrm{PE}$ & 6,7 & 6,9 & 7,0 & 7,1 & 7,0 & 6,9 & 7,3 & 6,9 \\
\hline \multirow{2}{*}{ Turb. } & PC & 5,6 & 482,8 & 321,8 & 241,8 & 18,1 & 18,3 & 241,4 & 177,1 \\
\hline & $\mathrm{PE}$ & 2,3 & 26,1 & 16,8 & 24,2 & 12,4 & 27,8 & 16,7 & 47,4 \\
\hline \multirow{2}{*}{$\mathrm{T}$} & PC & 18,3 & 19,0 & 20,3 & 20,3 & 19,3 & 21,7 & 20,3 & 20,3 \\
\hline & PE & 14,3 & 14,7 & 15,7 & 15,0 & 15,0 & 15,0 & 15,0 & 15,3 \\
\hline \multirow{2}{*}{$\mathrm{DBO}$} & PC & 1,4 & 18,7 & 16,0 & 23,1 & 26,8 & 35,1 & 10,6 & 19,1 \\
\hline & $\mathrm{PE}$ & 5,9 & 36,8 & 32,6 & 39,4 & 33,6 & 69,5 & 34,5 & 42,0 \\
\hline \multirow{2}{*}{ OD } & PC & 7,4 & 5,1 & 4,6 & 4,8 & 2,8 & 3,5 & 4,6 & 4,9 \\
\hline & $\mathrm{PE}$ & 8,6 & 7,8 & 6,2 & 5,7 & 4,2 & 5,0 & 7,1 & 4,7 \\
\hline \multirow{2}{*}{$\mathrm{NO}_{3}^{-}$} & PC & 0,09 & 0,98 & 1,32 & 2,58 & 2,23 & 5,24 & 1,89 & 1,39 \\
\hline & PE & 0,02 & 0,74 & 1,11 & 2,30 & 1,50 & 5,57 & 2,10 & 1,37 \\
\hline \multirow{2}{*}{$\mathrm{P}$} & PC & 0,02 & 0,02 & 0,02 & 0,02 & 0,02 & 0,02 & 0,02 & 0,01 \\
\hline & $\mathrm{PE}$ & 2,82 & 2,47 & 1,80 & 1,77 & 1,25 & 2,38 & 2,21 & 0,80 \\
\hline \multirow{2}{*}{ ST } & PC & 41,3 & 114,4 & 90,7 & 110,9 & 102,5 & 100,7 & 100,0 & 109,6 \\
\hline & PE & 65,8 & 66,9 & 81,7 & 87,8 & 104,4 & 112,0 & 128,7 & 101,3 \\
\hline \multirow{2}{*}{$\mathrm{CT}$} & PC & $9,6 \mathrm{E}+03$ & $1,4 \mathrm{E}+07$ & $1,8 \mathrm{E}+07$ & $2,0 \mathrm{E}+08$ & $4,3 \mathrm{E}+08$ & $6,2 \mathrm{E}+09$ & $9,0 \mathrm{E}+08$ & $2,0 \mathrm{E}+09$ \\
\hline & PE & $1,2 \mathrm{E}+03$ & $3,7 \mathrm{E}+07$ & $3,7 \mathrm{E}+07$ & $4,7 \mathrm{E}+07$ & $1,5 \mathrm{E}+06$ & $5,0 \mathrm{E}+06$ & $4,7 \mathrm{E}+05$ & $4,7 \mathrm{E}+07$ \\
\hline \multirow{2}{*}{ Qe } & PC & - & $1.334,3$ & $1.576,4$ & $9.161,5$ & 147,4 & 161,0 & $2.313,4$ & 519,3 \\
\hline & $\mathrm{PE}$ & - & 208,8 & 599,3 & $1.508,7$ & 44,2 & 39,1 & 739,2 & 227,6 \\
\hline
\end{tabular}

PC - Período chuvoso; PE - Período de estiagem; Tur. - Turbidez (UNT); T - temperatura ( $\left.{ }^{\circ} \mathrm{C}\right)$; DBO - demanda bioquímica de

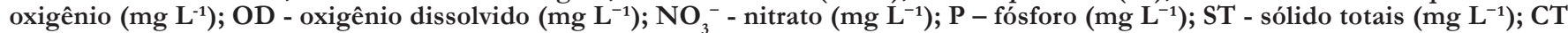
- coliformes termotolerantes (NMP $\left.100 \mathrm{~mL}^{-1}\right)$; e Qe - vazão ( $\mathrm{L} \mathrm{s}^{-1}$ )

resíduos sólidos das áreas urbanizadas e de partículas de solo das áreas agrícolas da bacia, tal como verificado por Cunha et al. (2013), Santi et al. (2012) e Silva et al. (2008).

Para os afluentes do Ribeirão Vermelho (P3, P5 e P7) houve diferenciação nos valores de ST em relação ao próprio Ribeirão Vermelho $(\mathrm{p}<0,05)$. Os afluentes drenam áreas estritamente urbanizadas e recebem muitos resíduos sólidos urbanos e resíduos de construção civil.

As concentrações de fósforo $(\mathrm{P})$ foram maiores no inverno. Sabe-se que o fósforo pode estar diretamente ligado aos sólidos em suspensão presentes nas águas, Bertol et al. (2011), e que também causam a turbidez. No entanto, a turbidez apresentou comportamento contrário. Neste caso, tal como relatado por Quevedo e Paganini (2011), a contribuição dos esgotos domésticos, por meio do aporte de sólidos dissolvidos, parece ter sobressaído ao arraste de fósforo dos solos, influenciando diretamente as concentrações deste elemento na água. Desta forma, maiores concentrações de DBO são consistentes com maiores concentração de P na água.

As concentrações de $\mathrm{P}$ no período de estiagem alcançaram valores de 60 a 140 vezes superiores aos observados no período chuvoso, com valores entre 0,80 e $2,82 \mathrm{mg} \mathrm{L}^{-1}$. Somente no período chuvoso as concentrações $\left(0,01\right.$ e $0,02 \mathrm{mg} \mathrm{L}^{-1}$ de $\left.\mathrm{P}\right)$ ficaram dentro do limite estabelecido pela legislação ambiental vigente para os cursos de água Classe 2 (BRASIL, 2005).

Diferentemente do fósforo, os maiores teores de nitratos observados na época de verão $(\mathrm{p}<0,05)$ se relacionam com os aportes exógenos da bacia de drenagem que estão relacionados com as atividades humanas baseadas na utilização de recursos naturais, e na emissão de resíduos para o ambiente, além do aporte oriundo da lixiviação de solos dedicados a agropecuária, e da deposição atmosférica mais intensa no período chuvoso (MOLISANI et al., 2013). Durante os períodos chuvosos, os escoamentos das águas pluviais transportam inúmeras espécies químicas, entre as quais o nitrito e o nitrato, que são muito solúveis em água - Silva et al., (2010), aumentando sua concentração nas águas.

Dentre as atividades antrópicas desenvolvidas na bacia do Ribeirão Vermelho estão as fontes relacionadas à urbanização como a geração e deposição inadequada de resíduos sólidos, do esgoto doméstico e escoamento urbano; e atividades agropecuárias. Parte da bacia possui características urbanas $(21,4 \%)$, e parte possui características rurais, sendo composta por: mata secundária (19,3\%), área agricultada (16,7\%), pastagem (32,6\%) e solo exposto $(6,2 \%)$; o restante $(3,9 \%)$ é ocupado por água (Figura 1). Vale ressaltar que, o principal complexo de nascentes e a cabeceira da bacia encontram-se sob uso predominante de pastagem. A pastagem existente na bacia apresenta algum estado de degradação em sua maior parte, com perda de vigor e produtividade (NEVES JUNIOR et al., 2013). Tal fato facilita processos erosivos e favorece o escoamento superficial.

Tais atividades podem ser fontes representativas na emissão de matéria orgânica nos cursos de água o que reflete diretamente nos elevados valores de $\mathrm{DBO}$ observados nas 


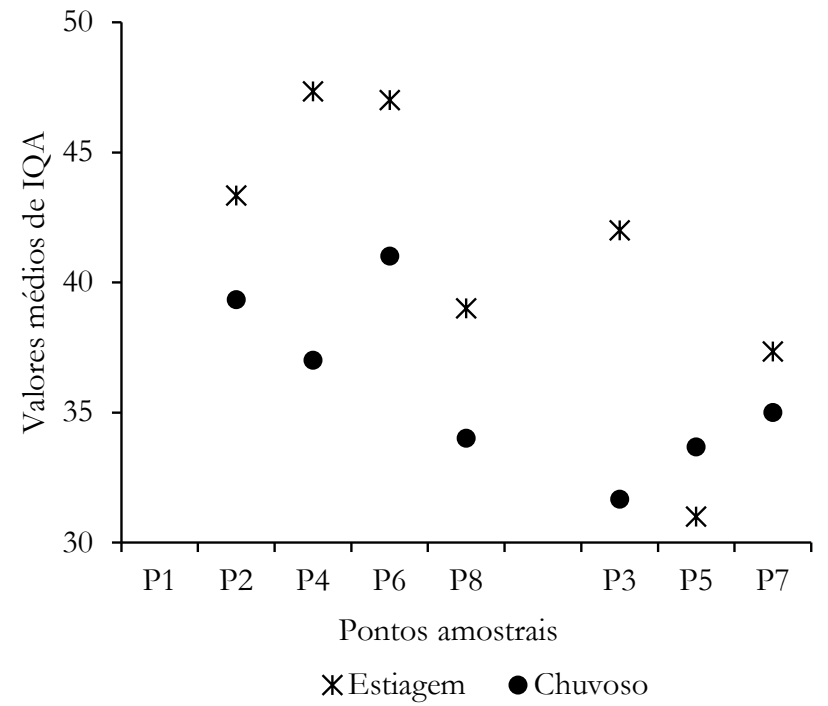

Figura 4 - Média da variação espaço-temporal do Índice de Qualidade da Água em diferentes períodos do ano (chuvoso e estiagem), nos diferentes pontos amostrais ao longo do Ribeirão Vermelho (P1, P2, P4, P6 e P8) e seus principais afluentes (P3, P5 e P7)

diferentes amostragens. Maiores valores de DBO foram observados no inverno, período com menor incidência de chuvas e consequente aumento na concentração dos poluentes devido às menores vazões nos cursos de água.

Os maiores valores encontrados de oxigênio dissolvido (OD) na nascente (P1), em relação aos demais pontos amostrais já era esperado pelo fato de ser o único ponto de coleta que ainda possui alguma de suas características naturais que contribuem para a proteção quanto os impactos causados pela urbanização. Ao contrário do observado por Oliveira et al. (2008), foram verificados maiores valores médios de OD no inverno, apesar de serem observados maiores valores de DBO neste período. Sabe-se que os microrganismos consomem o OD das águas para degradar a matéria orgânica. No entanto, acredita-se que as menores temperaturas no inverno tenham reduzido a atividade metabólica microbiana o que reduziu o consumo de OD. Além disso, em menores temperaturas, a água tem maior capacidade de manter maiores concentração de OD. Ao longo dos cursos de água, a ausência de cobertura ciliar, permite que a radiação incida diretamente sobre a água o que aumenta a temperatura da água principalmente no verão, reduzindo o nível de OD (OLIVEIRA et al., 2009).

Outro fator que pode ter influenciado diretamente a concentração de OD nas águas no inverno, foram as elevadas concentração de nutrientes (nitrato e fósforo) que permitem o desenvolvimento de plantas aquáticas e algas que produzem $O D$ para o ambiente por meio da fotossíntese. Sabe-se que o papel de plantas aquáticas e algas é mais importante nos cursos de água lênticos. No entanto, com as reduzidas vazões e turbidez no período de inverno houve redução da velocidade de escoamento, redução da profundidade e maior incidência de luz o que pode ter favorecido o desenvolvimentos dessas espécies aquáticas.

A presença de coliformes termotolerantes (CT) na nascente do Ribeirão Vermelho pode estar associada à presença frequente de bovinos que utilizam a mesma como fonte para o consumo. Tal fato foi evidenciado por Pinto et al. (2012), entretanto em menor intensidade. Os autores verificaram entre 25 e $300 \mathrm{NMP} 100 \mathrm{~mL}^{-1}$. Enquanto neste trabalho a variação de CT ficou entre 1.200 e $9.600 \mathrm{NMP} 100 \mathrm{~mL}^{-1}$. O lançamento de esgotos domésticos, provavelmente, foi a principal contribuição para o aumento dos CT ao longo do Ribeirão Vermelho e seus afluentes, impedindo o uso desses mananciais para o desenvolvimento de atividades de contato primário (MINAS GERAIS, 2008).

A partir dos resultados das variáveis físico-químicas e bacteriológicas (Tabela 4) foi possível determinar o Índice de Qualidade da Água (IQA) para os cursos de água da bacia do Ribeirão Vermelho. Os valores do IQA variaram entre 64 (P1) a 31 (P5) no período do verão e 67 (P1) a 33 (P5) no período de inverno (Figura 4).

A água da nascente do Ribeirão Vermelho no ano de 2011 pôde ser classificada, de acordo com IGAM (2005), como de qualidade média a partir dos valores de IQA. Os maiores valores de IQA encontrados para a nascente podem estar relacionados com a menor exploração da área observada na cabeceira deste curso de água quando comparado ao impacto gerado pela cidade. No entanto, por se tratar de uma nascente o valor é relativamente baixo. Foram encontrados valores relativamente elevados de DBO, fósforo e coliformes termotolerantes. Segundo Brasil (2005), as águas Classe 1 devem ter valores de $\mathrm{DBO}$, fósforo e coliformes termotolerantes inferiores a $3 \mathrm{mg}$ $\mathrm{L}^{-1}, 0,1 \mathrm{mg} \mathrm{L}{ }^{-1}$, e 2,0 E+02 NMP $100 \mathrm{~mL}^{-1}$. Estes parâmetros foram superados pelos valores observado no P1, pelo menos no período de inverno. Além disso, por se tratar de uma nascente, P1 deveria apresentar as condições da Classe Especial, em que devem ser mantidas as condições naturais do corpo de água (BRASIL, 2005). A nascente do Ribeirão Vermelho avaliada encontra-se à jusante de um loteamento na área urbana da cidade de Lavras. Apesar de haver junto à nascente uma área de preservação permanente composta por mata ciliar, há também pastagens e o gado tem livre acesso à área ao redor da nascente, constituindo uma fonte de poluição difusa.

Os demais pontos amostrais ao longo do Ribeirão Vermelho e de seus afluentes tiveram suas águas classificadas como de qualidade ruim. Apesar de não haver diferença significativa ao longo dos pontos observados, verificou-se uma tendência do decréscimo da qualidade da água em direção à foz do Ribeirão Vermelho.

Kemerich et al. (2012), estudando uma microbacia com situações de urbanização obtiveram resultados semelhantes, em que a principal causa da alteração da qualidade da água foi o esgoto doméstico. Portanto, a dinâmica de uso e ocupação do solo de forma desordenada na área da microbacia do Ribeirão Vermelho contribui substancialmente para a degradação da qualidade da água, e o fator determinante se deve às cargas poluidoras de origem doméstica (esgotos sanitários e resíduos sólidos) e agropastoris. O resultado reflete o observado in loco quando da amostragem da água, pois a área, na sua maior parte, apresenta lançamento clandestino de esgoto no corpo d'água, áreas de erosão, degradação da cobertura vegetal e transporte de lixo, devido ao acúmulo nas margens. 
Em relação ao grau de trofia, não foram encontradas diferenças significativas entre os períodos amostrados, como também não foi verificado diferenças significativas entre os pontos ao longo do Ribeirão Vermelho e os afluentes avaliados (Figura 5). Vale ressaltar que esta avaliação levou apenas em consideração as concentrações de fósforo total, sendo que para ter um completo diagnóstico do índice de trofia de um corpo d'água seria necessário levar em consideração também a concentração de clorofila a (LAMPARELLI, 2004).

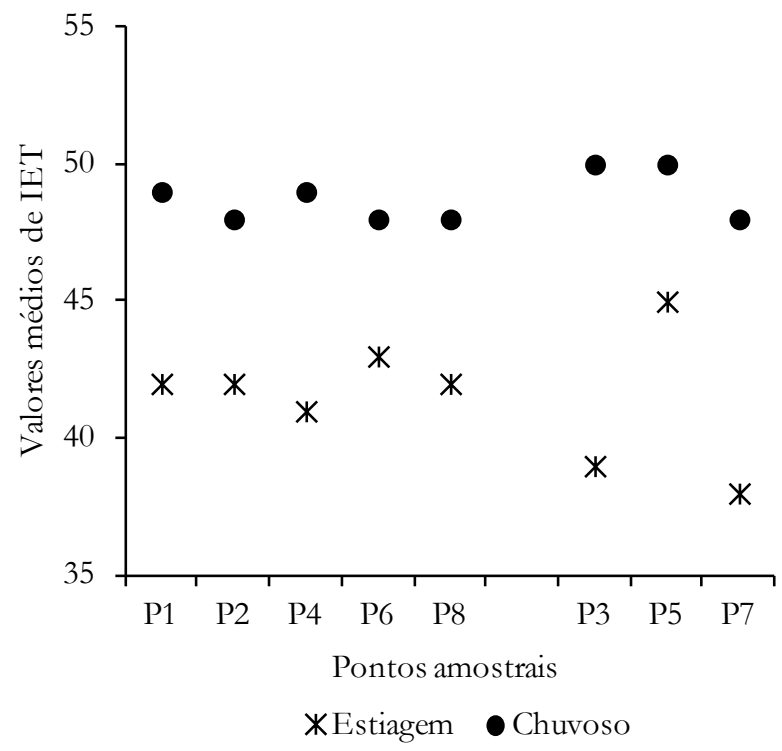

Figura 5 - Valores médios de IET nas amostras de água coletadas em diferentes períodos do ano (chuvoso e estiagem), nos diferentes pontos amostrais ao longo do Ribeirão Vermelho (P1, P2, P4, P6 e P8) e seus principais afluentes (P3, P5 e P7)

Apesar de não haver um padrão entre as estações avaliadas, observa-se uma variabilidade sazonal nos valores do índice de estado trófico. Segundo Bello e Guandique (2011), a variabilidade é em virtude da variabilidade sazonal dos processos ambientais que têm influência sobre o grau de eutrofização de um corpo hídrico. Em geral, segundo os autores, no início da primavera, com o aumento da temperatura da água, maior disponibilidade de nutrientes e condições propícias de penetração de luz na água, é comum observar um incremento do processo após o inverno, em que se mostra menos intenso.

Os dados de índice de estado trófico revelam um ambiente oligotrófico a eutrófico, da nascente a foz do Ribeirão Vermelho, indicativo de uma maior entrada de nutrientes e consequente produção primária. Apesar de haver junto à nascente uma área de preservação permanente composta por mata ciliar, parece que a nascente sofreu interferência da comunidade circunvizinha, devido às elevadas concentrações de fósforo observadas. Farage et al. (2010) também obtiveram valores elevados de fósforo $\left(0,08\right.$ e $\left.0,11 \mathrm{mg} \mathrm{L}^{-1}\right)$ na nascente do Rio Pomba, na zona da mata mineira, e atribuíram o fato à interferência antrópica.

Atividades antrópicas como o lançamento de esgotos, mesmo que tratados, e a poluição difusa proveniente da agropecuária degradam a qualidade das águas, tal como observado por Ortega e Carvalho (2013). Os maiores Índices de Estado Trófico obtidos para o Ribeirão Vermelho podem estar associados ao excesso de esgotos, tendo em vista que se trata de uma área extremamente urbanizada, e ao despejo dos efluentes tratados por uma das estações de tratamentos de esgotos de Lavras, a ETE Ribeirão Vermelho, principalmente em P6 e P8.

Fia et al. (2009) ao avaliarem cursos de água de áreas urbanizadas e afluentes à Lagoa Mirim no Rio Grande do Sul, obtiveram IET variando entre mesotrófico e hipereutrófico, além de concentrações médias de fósforo entre 0,60 e 57,5 mg $\mathrm{L}^{-1}$, durante três anos de monitoramento. Já Farage et al. (2010) obtiveram para o Rio Pomba, na região do Alto Rio Pomba durante o período chuvoso, IET entre 57 (mesotrófico) e 89 (hipereutrófico), e concentrações de fósforo entre 0,07 e 0,59 $\mathrm{mg} \mathrm{L^{-1 }}$.

\section{CONCLUSÕES}

Menores valores de IQA e maiores valores de IET foram observados no período chuvoso em relação ao de estiagem. Tanto no inverno quanto no verão, o Ribeirão Vermelho e seus principais afluentes apresentaram qualidade de água ruim, exceto na nescente.

Diante dos resultados obtidos pode-se concluir que o Ribeirão Vermelho e seus afluentes apresentam influência antrópica constatada pela entrada de matéria orgânica e de nutrientes nos sistemas hídricos apresentado pelo lançamento de esgoto doméstico sem tratamento e pela agropecuária presente na rede de drenagem da bacia.

Tornam-se necessárias melhorias no sistema de esgotamento sanitário e do manejo do solo da bacia hidrográfica do Ribeirão Vermelho para melhorar a qualidade da água na bacia.

\section{REFERÊNCIAS}

ASSOCIAÇÃO BRASILEIRA DE NORMAS TÉCNICAS. Preservação e técnicas de amostragem de afluente líquidos e corpos receptores - Procedimento. Rio de Janeiro: ABNT, 1987. 22p.

AKKOYUNLU, A.; AKINER, M.E. Pollution evaluation in streams using water quality indices: A case study from Turkey's Sapanca Lake Basin. Ecological Indicators, Amsterdam, v.18, n.1, p.501-511, 2012.

APHA. American Public Health Association; AWWA - American Water Works Association; WEF. Water Environment Federation. Standard methods for the examination of water and wastewater. $21^{\text {th }} \mathrm{ed}$. Washington: APHA/AWWA/WEF, 2005, [s.n.].

AZEVEDO NETTTO, J. M. Manual de hidráulica. 8.ed. São Paulo: Blucher, 1998. 680p.

BELLO, F.H.; GUANDIQUE, M.E. Diagnóstico ambiental do 
meio aquático do rio Ipanema, Sorocaba/SP. HOLOS Environment, v.11, n.2, p.94-105, 2011.

BERTOL, I.; GOBBI, E.; BARBOSA, F.T.; PAZ-FERREIRO, J.; GEBLER, L.; RAMOS, J.C.; WERNER, R.S. Erosão hídrica em campo nativo sob diversos manejos: perdas de água e solo e de fósforo, potássio e amônio na água de enxurrada. Revista Brasileira de Ciência do Solo, v.35, p.1421-1430, 2011.

BRASIL. Conselho Nacional de Meio Ambiente - CONAMA. Resolução no 357, de 17 de março de 2005. Dispõe sobre a classificação dos corpos de água e diretrizes ambientais para o seu enquadramento, bem como estabelece as condições e padrões de lançamento de efluentes, e dá outras providências. Brasília: Diário Oficial da União, n. 053, págs. 58-63, 18/03/2005.

BRASIL. Ministério da Agricultura e Reforma Agrária. Normais climatológicas 1961-1990. Brasília: MARA, 1992. 84 p.

BUZELLI, G.M.; CUNHA-SANTINO, M.B. Análise e diagnóstico da qualidade da água e estado trófico do reservatório de Barra Bonita, SP. Revista Ambiente \& Água, Taubaté, v.8, n.1, 2013.

CETESB. Companhia Ambiental do Estado de São Paulo. 2013. Qualidade da água. Disponível: http://www.cetesb.sp.gov. br/agua/\%C3\%A1 guas-superficiais / 108- $\%$ C3\%ADndices-dequalidade-das-\%C3\%A1guas. Acesso em: 10 Out 2013.

CORADI, P. C.; FIA, R.; PEREIRA-RAMIREZ, O. Avaliação da qualidade da água superficial dos cursos de água do município de Pelotas-RS, Brasil. Revista Ambiente \& Água, v. 4, p. 46-56, 2009 a.

CORADI, P. C.; PEREIRA-RAMIREZ, O.; FIA, R.; MATOS, A. Qualidade da água superficial da bacia hidrográfica da Lagoa Mirim. Revista de Ciências Ambientais, v. 3, p. 53-64, 2009b.

CUNHA, R.W.; GARCIA JR., M.D.N.; ALBERTONI, E.F.; SILVA, C.P. Qualidade de água de uma lagoa rasa em meio rural no sul do Brasil. Revista Brasileira de Engenharia Agrícola e Ambiental, Campina Grande, v.17, n.7, p.770-779, 2013.

ESTEVES, F.A. Fundamentos da limnologia. 3. ed. Rio de Janeiro: Interciência, 790p., 2011.

FARAGE, J.A.P.; MATOS, A.T.; SILVA, D.D.; BORGES, A.C. Determinação do índice de estado trófico para fósforo em pontos do rio pomba. Engenharia na agricultura, v.18, n.4, p.322-329, 2010.

FERREIRA, D.F. Sisvar: a computer statistical analysis system. Ciência e Agrotecnologia, Lavras, v. 35, n.6, p. 1039-1042, 2011.

FIA, R.; MATOS, A.T.; CORADI, P.C.; PEREIRA-RAMIREZ, O. Estado Trófico da água na bacia hidrográfica da Lagoa Mirim, RS, Brasil. Revista Ambiente e Água, v.4, n.1, p.132-141, 2009.

IBGE. Instituto Brasileiro de Geografia e Estatística. Censo Demográfico 2010. Brasília: Imprensa Nacional/Diário Oficial da União, no 211, Seção 1, 2010. p.110.

IGAM. Instituto Mineiro de Gestão das Águas. Sistema de cálculo da qualidade da água (SCQA): Estabelecimento das Equações do índice de Qualidade das Águas (IQA). Relatório 1. 2005. Disponível em: < http://aguas.igam.mg.gov.br/aguas/downloads/ SCQA_final.pdf>. Acesso em: 10 out. 2013.

IGAM. Instituto Mineiro de Gestão das Águas. Indicadores de qualidade. Disponível em: <http://comites.igam.mg.gov.br/ boletim-qualidade-das-aguas $/ 1650$-indicadores-de-qualidade $>$. Acesso em: 10 Out 2013.

KEMERICH, P.D.C.; SILVA, R.F.; REQUE, P.T. Determinação do índice de qualidade da água do arroio esperança. Revista do Centro de Ciência Naturais e Exatas, v.34, n.2, p.83-98, 2012.

LAMPARELI, M.C. Graus de trofia em corpos de água do estado de São Paulo: avaliação dos métodos de monitoramento. 2004. 207 f. Tese (Doutorado em Ecossistemas Terrestres e Aquáticos) Universidade de São Paulo, Instituto de Biociências, São Paulo, 2004.

LEMOS, M.; FERREIRA NETO, M.; DIAS, N.S. Sazonalidade e variabilidade espacial da qualidade da água na Lagoa do Apodi, RN. Revista Brasileira de Engenharia Agrícola e Ambiental, Campina Grande, v.14, n.2, p.155-164, 2010.

MINAS GERAIS. COPAM - Conselho de Política Ambiental; CERH - Conselho Estadual de Política Ambiental. Deliberação Normativa Conjunta COPAM / CERH-MG nº 01, de 05 de maio de 2008. Dispõe sobre a classificação dos corpos de água e diretrizes ambientais para o seu enquadramento, bem como estabelece as condições e padrões de lançamento de efluentes, e dá outras providências. Publicação - Diário do Executivo - "Minas Gerais" - 13/05/2008.

MOLISANI, M.M.; ESTEVES, F.A.; LACERDA, L.D.; REZENDE, C.E. Emissões naturais e antrópicas de nitrogênio, fósforo e metais para a bacia do rio Macaé (Macaé, RJ, Brasil) sob influência das atividades de exploração de petróleo e gás na bacia de Campos. Química nova, v. 36, n. 1, p. 27-33, 2013.

NEVES JUNIOR, A. F.; SILVA, A. P.; NORONHA, N. C.; CERRI, C. C. Sistemas de manejo do solo na recuperação de uma pastagem degradada em Rondônia. Rev. Bras. Ciênc. Solo, Viçosa, v.37, n.1, p.232-241, 2013.

OLIVEIRA, L.C.; GOMES, B.M.; BAUMGARTNER, G.; SEBASTIEN, N.Y. Variação espacial e temporal dos fatores limnológicos em riachos da microbacia do Rio São Francisco Verdadeiro. Engenharia Agrícola, v.28, n.4, p.770-781, 2008.

OLIVEIRA, T.M.B.F.; DI SOUZA, L.; CASTRO, S.S.L. Dinâmica da série nitrogenada nas águas da bacia hidrográfica Apodi/ Mossoró - RN - Brasil. Eclética Química, v.34, n.3, p.17-26, 2009. 
ORTEGA, D.J.P.; CARVALHO, S.L. Avaliação dos efeitos das atividades antropóficas nos recursos hídricos na sub-bacia hidrográfica do Córrego do Ipê - SP. Revista Brasileira de Recursos Hidricos, v.18, n.3, p.97-108, 2013.

PINTO, L.V.A.; ROMA, T.N.; BALIEIRO, K.G.C. Avaliação qualitativa da água de nascentes com diferentes usos do solo em seu entorno. Cerne, Lavras, v.18, n.3, p.495-505, 2012

QUEVEDO, C.M.G.; PAGANINI, W.S. Impactos das atividades humanas sobre a dinâmica do fósforo no meio ambiente e seus reflexos na saúde pública. Ciência \& Saúde Coletiva, v.16, n.8, p.3529-3539, 2011.

SANTI, G.M.; FURTADO, C.M.; MENEZES, R.S.; KEPPELER, E.C. Variabilidade espacial de parâmetros e indicadores de qualidade da água na sub-bacia hidrográfica do Igarapé São Francisco, Rio Branco, Acre, Brasil. Ecología Aplicada, Lima, v.11, n.1, p.23-31, 2012.

SILVA, A. E. P.; ANGELIS, C. F.; MACHADO, L. A. T.; WAICHAMAN, A. V. Influência da precipitação na qualidade da água do Rio Purus. Acta Amazonica, Manaus, v.38, n.4, p.733742, 2008.

SILVA, G.S.; MIOLA, S.; SILVA G.S.; SOUSA, E.R. Avaliação da qualidade das águas do Rio São Francisco Falso, tributário do reservatório de Itaipu, Paraná. Eclética Química, v.35, n.3, p.117-122, 2010 .

TOLEDO JR., A.P. Informe preliminar sobre os estudos para obtenção de um índice para avaliação simplificada do estado trófico de reservatórios de regiões quentes tropicais. São Paulo: CETESB, 1990. 11p. Relatório técnico.

TYAGI, S.; SHARMA, B.; SINGH, P.; DOBHAL, R. Water quality assessment in terms of water quality index. American Journal of Water Resources, Middleburg, v. 1, n.3, p.34-38, 2013.

WENGRAT, S.; BICUDO, D.C. Spatial evaluation of water quality in an urban reservoir (Billings Complex, southeastern Brazil). Acta Limnologica Brasiliensia, Rio Claro, v.23, n.2, p.200-216, 2011.

YU, D.; SHI, P.; LIU, Y.; XUN, B. Detecting land use-water quality relationships from the viewpoint of ecological restoration in an urban area. Ecological Engineering, Amsterdam, v.53, n.1, p.205-216, 2013.

ZHOU, H.; JIANG, H.; HUANG, Q. Landscape and water quality change detection in urban wetland: a post-classification comparison method with IKONOS data. Procedia Environmental Sciences, Amsterdam, v.10, Part B, p. 1726-1731, 2011. 